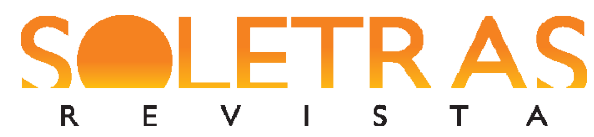

\title{
A leitura dos nativos digitais: uma abordagem psicolinguística
}

\author{
Joana Angélica da Silva de Souza ${ }^{1}$ \\ Eduardo Kenedy ${ }^{2}$ \\ Universidade Federal Fluminense
}

\begin{abstract}
Resumo: Considerando o fenômeno conhecido nas neurociências como plasticidade cerebral (SCHWARTZ, 2002) e o escopo teórico da Psicolinguística sobre leitura, pesquisas (SMALL, 2009; CARR, 2011) sugerem que o uso da Internet favorece o desenvolvimento da capacidade de realizar múltiplas tarefas, o que teria um encargo cognitivo preocupante: a perda gradativa da nossa capacidade de concentração e reflexão. Esse quadro suscita duas perguntas básicas: (i) Como essas mudanças em nosso comportamento cognitivo podem afetar nossa capacidade de decodificar e atribuir significados a textos escritos? (ii) As novas gerações, os chamados os nativos digitais (PRENSKY, 2001), estão mais suscetíveis a essas mudanças pela exposição precoce aos meios virtuais? Definimos como objetivos do trabalho a verificação de possíveis dificuldades na compreensão de textos e retenção de informações por parte dos nativos digitais e averiguação de possíveis diferenças na leitura em meio digital e impresso por parte dos nativos digitais e dos imigrantes digitais. Utilizamos a metodologia experimental, através de uma tarefa de preenchimento de lacunas no modelo do Teste de Cloze (TAYLOR, 1953) e um teste de memória/reconhecimento das palavras apresentadas no texto. As variáveis dependentes foram o número de palavras preenchidas de forma coerente com o sentido do texto e o número de palavras recordadas no teste de memória, enquanto as variáveis independentes foram a classificação em nativo digital ou imigrante digital, o meio utilizado para a leitura, papel ou computador, e o tamanho do texto, curto ou longo. Os sujeitos não foram expostos às mesmas condições experimentais (distribuição entre sujeitos).
\end{abstract}

Palavras-chave: Leitura. Compreensão leitora. Cognição. Internet. Psicolinguística.

\section{Introdução}

O presente artigo tem como objetivo apresentar as consequências, do ponto de vista cognitivo, do uso excessivo de Internet e outras ferramentas digitais para as atividades de leitura e compreensão de textos. A escolha pelo tema do impacto da Internet para a leitura se dá pelo fato de que estamos ficando conectados cada vez mais horas por dia. Já o interesse pela compreensão de textos surge da observação da falta de proficiência nas tarefas de leitura em praticamente todas as camadas socioculturais no Brasil.

\footnotetext{
${ }^{1}$ Doutoranda do Programa de Pós-Graduação em Estudos da Linguagem da Universidade Federal Fluminense. E-mail: joana.souza.trad@gmail.com.

${ }^{2}$ Doutor em Linguística. Docente do Programa de Pós-Graduação em Estudos da Linguagem da Universidade Federal Fluminense. E-mail: edu.kenedy@gmail.com.
} 


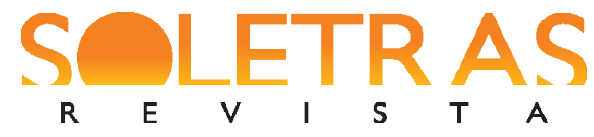

N. 33 ï 2017.1 ï JOANA ANGÉLICA DA SILVA DE SOUZA EDUARDO KENEDY

Nas últimas décadas, o uso de tecnologias como computadores, tablets e celulares do tipo smartphone se intensificou e se popularizou em todas as camadas sociais e faixas etárias, no Brasil e em diversos outros países. Segundo dados do IBGE, ñno Brasil, o percentual de pessoas de 10 anos ou mais de idade que acessaram a Internet passou de 20,9\% (31,9 milhões) em 2005 para 46,5\% (77,7 milhões) em 2011ò(IBGE, 2011).

A tendência é que tais números aumentem a cada dia, já que as crianças que nascem agora já ficam imersas no universo digital desde a primeira infância e suas vidas e atividades cotidianas estão profundamente ligadas aos meios digitais e à Internet. Nesse sentido, Prensky (2001) inaugura, em seu artigo Digital Natives, Digital Immigrants, o termo ñativos digitaisò para se referir à parcela da população que nasceu e cresceu já dentro dessa nova lógica da vida social. Para ele, essas pessoas das gerações mais jovens com acesso diário aos meios digitais interagem com o mundo e com o conhecimento de forma mais dinâmica, rápida e menos linear que as pessoas que nasceram antes, os chamados ñimigrantes digitaisò.

Para alguns autores (SMALL, 2009; CARR, 2011), esse cenário de uso exacerbado de tecnologias virtuais é preocupante, sobretudo no que se refere às diferenças da leitura em meio digital e em papel:

Uma página de texto on-line vista através da tela de um computador pode parecer similar a uma página de texto impresso. Mas rolar ou clicar através de um documento da web envolve ações físicas e estímulos sensoriais muito diferentes daqueles envolvidos em segurar e virar as páginas de um livro ou uma revista. Pesquisas ${ }^{3}$ mostraram que o ato cognitivo de ler se baseia não apenas no sentido da visão, mas também no tato. É tátil assim como visual. (CARR, 2011, p. 129).

Pesquisas recentes (SMALL, 2009; CARR, 2011) têm demonstrado através, inclusive, de técnicas refinadas de neuroimagem que o nosso cérebro se comporta de forma diferente em ambientes virtuais, em comparação com a interação física com o mundo real, e, mais do que isso, que ele é fisicamente alterado de acordo com as habilidades que desenvolvemos nesses ambientes digitais. $\mathrm{Na}$ realidade, toda experiência realizada de forma repetida influencia nossas sinapses devido à propriedade do cérebro denominada plasticidade cerebral ou neuroplasticidade.

\footnotetext{
${ }^{3}$ Anne Mangen, ñHypertext Fiction Reading: Haptics and Immersionò, Journal of Research in Reading, 31 n. 4, 2008, p. 404-419.
} 


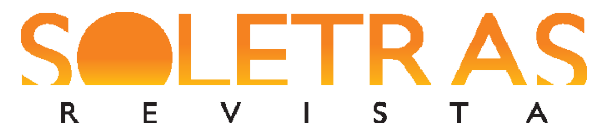

N. 33 ï 2017.1 ï JOANA ANGÉLICA DA SILVA DE SOUZA EDUARDO KENEDY

Para Carr, estamos presenciando o surgimento de uma geração de leitores superficiais, como sugere o próprio título do seu livro, A geração superficial: o que a internet está fazendo com os nossos cérebros (CARR, 2009), que reúne diversas pesquisas sobre o tema. Visões catastróficas ou demasiadamente esperançosas à parte, o que se conclui é que há uma evidente necessidade de que voltemos nosso pensamento e nossos esforços enquanto estudiosos da linguagem e da mente para entender em que medida esse cenário está afetando nossa cognição.

No presente artigo, focalizaremos a questão da leitura e da compreensão de textos e tal escolha se deve ao fato de que podemos observar no meio pedagógico uma crescente preocupação com o desenvolvimento da habilidade da leitura desde as séries iniciais da formação dos alunos. Para a área pedagógica e, portanto, para a sociedade em geral, os estudos de psicolinguística que se voltam para os aspectos cognitivos da leitura são aliados essenciais. É justamente nessa parceria que encontramos a justificativa para a escolha do tema e da linha teórica que norteia o presente trabalho. Pois, conforme já dito, a leitura é um dos desafios da pedagogia e da formação de professores, como salienta Morais (1996):

(...) a leitura é indiscutivelmente um problema da sociedade. O desenvolvimento econômico é condicionado pela possibilidade que terão todos os homens e mulheres ativas (e não apenas certas camadas sociais) de tratar a informação escrita de uma maneira eficaz (MORAIS, 1996, p. 1920).

Sendo assim, descreveremos a revisão da literatura sobre leitura, a partir do escopo teórico da psicolinguística, relacionando ao tema do impacto cognitivo da Internet. Em seguida, apresentaremos o experimento realizado, bem como seus resultados e a análise dos dados coletados. Por fim, indicaremos o que os resultados obtidos sugerem e como esperamos que a presente pesquisa contribua para futuros estudos que relacionam o uso de Internet à habilidade leitora.

\section{Revisão da literatura}

O presente trabalho se insere no escopo teórico da Psicolinguística Experimental (CABRAL, 1986), que caminha no sentido de estabelecer interconexões com diversas outras 


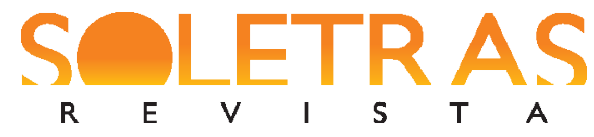

N. 33 ï 2017.1 ï JOANA ANGÉLICA DA SILVA DE SOUZA EDUARDO KENEDY

áreas do conhecimento e tem como base os estudos de Psicologia voltados para a cognição humana, de onde herda a metodologia experimental para a obtenção de dados.

No que se refere à leitura, existem duas abordagens principais para o estudo do processamento do texto escrito: a abordagem cognitiva e a abordagem global. A abordagem cognitiva se centra na visão de que a decodificação é a etapa mais importante do processo de aprendizagem da leitura e é utilizada por autores como Cabral (1986; 2003), Morais (1996), Capovilla (2004) e Dehaene (2009), que argumentam que antes de a criança compreender o que lê, é preciso que ela domine a identificação de letras, sílabas e palavras e consiga fazer a correlação entre as unidades mínimas da escrita e da fala. Já a abordagem global, utilizada por Foucambert (1994) e Smith (2003), centra-se na importância dos sentidos prévios construídos pelo leitor, na construção do conhecimento durante a leitura e na interatividade do processo de ler. Ambas as propostas serão consideradas na presente pesquisa a fim de fornecer um escopo teórico mais abrangente para nossas análises.

A capacidade de ler é uma forma específica da capacidade da mente de transformar representações de entrada (input) em representações de saída (output), ou seja, transformar um determinado estímulo visual em representação fonológica na forma de informação a ser utilizada pelo resto do sistema cognitivo. É importante ressaltar que ainda que o objetivo do ato de ler seja a compreensão, não se pode dizer que os processos de ler e compreender se identificam, pois, a decodificação do material escrito e transformação em matéria fonológica é parte imprescindível do ato de ler. Nas palavras de Morais, ñ leitura não atinge seu objetivo sem compreensão, todavia os processos específicos da leitura não são processos de compreensão, mas que levam à compreensãoò (MORAIS, 1996, p. 114):

(...) competências lexicais (isto é, nosso conhecimento do sentido das palavras), além de processos de análise sintática e de integração semântica; utilizamos até nosso conhecimento de mundo, nossa experiência pessoal, mas todos esses processos e conhecimentos também atuam quando compreendemos a linguagem falada. Processos e conhecimentos desse tipo são desenvolvidos na criança bem antes que ela aprenda a ler. (MORAIS, 1996, p. 114).

Nos últimos anos, os avanços tecnológicos na área de neuroimagem permitiram que os neurocientistas verificassem com precisão áreas do cérebro que são ativadas durante a atividade de leitura e, como consequência, estamos dando passos mais largos no sentido de 


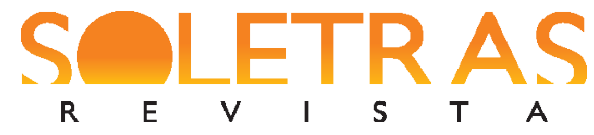

compreender as engrenagens dessa tão complexa atividade humana, conforme nos explica Dehaene (2009):

Advances in psychology and neuroscience over the last twenty years have begun to unravel the principles underlying the brainôs reading circuits. (é ) On this empirical ground, a theory of reading is materializing. It postulates that the brain circuitry inherited from our primate evolution can be co-opted to the task of recognizing printed words (DEHAENE, 2009, p. $\left.48^{4}\right)^{5}$

Como já dito, a leitura é uma atividade de alta complexidade, que envolve diversos aspectos da cognição humana, tais como a linguagem, a memória, o pensamento, a inteligência e a percepção (ADAMS, 1999; GARROD; DANEMAN, 2003). É importante pontuar também que na leitura satisfatória de um texto estão envolvidos quatro processos básicos: decodificação, compreensão, interpretação e retenção (CABRAL, 1986). Dentro desses quatro processos, existem diversos subprocessos, conforme podemos depreender pelo excerto a seguir:

Os subprocessos que constituem o ato da leitura (considerando textos de prosa) vão desde as fixações precedidas e seguidas dos movimentos em sacadas, reconhecimento da palavra, enfatiamento de unidades básicas de significação na sentença, captação das funções das entidades que as compõem e de seu relacionamento, apropriação do sentido adequado das palavras ao contexto, com eliminação de outros sentidos possíveis (polissêmicos ou ambíguos), relacionamento das significações entre as sentenças, utilização de todos os elementos correferenciais e, finalmente, as inferências que darão unidade ao texto em exame. Resumidamente, poderemos dizer que há quatro etapas decisivas no processo da leitura: decodificação, compreensão, interpretação e retenção (CABRAL, 1986, p. $8)$.

Vale ressaltar que em um indivíduo adulto, que já automatizou de forma fluente e adequada o processo da leitura, esses processos e subprocessos não necessariamente ocorrem de forma linear, um após o outro e unidirecionalmente, o que faz com que a leitura não seja

\footnotetext{
${ }^{4} \mathrm{O}$ livro Reading in the brain: a new science of how we read, de Dehaene, foi lido em sua versão digital para Kindle e, portanto, no lugar do número da página da citação, usaremos para fins de referência o número da posição.

${ }^{5}$ Os avanços na psicologia e na neurociência nos últimos vinte anos começaram a desvendar os princípios subjacentes aos circuitos de leitura do cérebro. (...) Neste campo empírico, uma teoria da leitura está se materializando. Ela postula que o nosso circuito cerebral herdado da evolução dos primatas pode ser cooptado para a tarefa de reconhecer palavras impressas (tradução nossa).
} 


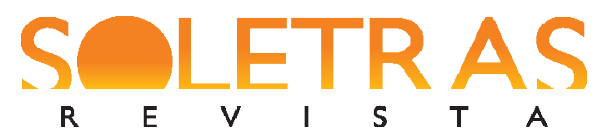

N. 33 ï 2017.1 ï JOANA ANGÉLICA DA SILVA DE SOUZA EDUARDO KENEDY

caracterizada como um processo bottom-up ou ascendente (STERNBERG, 2012). Podemos dizer que existem três modelos para explicar como ocorre o processamento da leitura. Foucambert (1994) sintetiza o modelo ascendente e descendente da seguinte forma:

- o modelo ascendente (bottom up), que parte das letras para as sílabas, as palavras, as frases... e funciona com base na decodificação, indo do simples ao complexo;

- o modelo descendente (top down), que parte do conjunto (da Gestalt) e caminha do sentido para os elementos que o expressam (FOUCAMBERT, 1994, p. 53).

O terceiro e último modelo é chamado de interativo e é o mais reconhecido, integrando os dois modelos acima abordados. Para o modelo interativo, durante a atividade de leitura ocorre uma sucessão de etapas de recuperação fonológica, morfossintática, semântica, discursiva e pragmática. Tais etapas muitas vezes ocorrem simultaneamente e fazem com que ler seja um fenômeno complexo do ponto de vista cognitivo e profundamente relacionado às práticas sociais e culturais do indivíduo. Em Kleiman (2007), temos a consideração de como se dá essa sucessão de etapas.

O processamento do texto, isto é, o agrupamento e transformação de unidades de um nível (por exemplo, letras) em unidades significativas de outro nível (por exemplo, palavras) se faz tanto a partir do conhecimento prévio e das expectativas e objetivos do leitor (chama-se esse tipo de processamento descendente ou de-cima-para-baixo) quanto a partir de elementos formais do texto à medida que o leitor os vai percebendo (chamase esse tipo de processamento ascendente, ou de-baixo-para-cima) (KLEIMAN, 2007, p. 55).

Cabral (2003) sintetizou os processos mencionados acima e dividiu o ato de ler em sete etapas: (1) motivação, (2) pré-leitura, (3) movimentos oculares, (4) decodificação, (5) atribuição de sentidos, (6) interpretação e (7) retenção. A partir dessa divisão e paralelamente à análise dos dados advindos do experimento realizado, poderemos chegar a conclusões sobre o efeito da Internet no processamento da leitura e, mais especificamente, sobre como as etapas do ato de ler são influenciadas pelo uso dos meios digitais.

Cabe mencionar aqui que toda leitura culmina na retenção das informações e impressões deixadas pelo texto. A retenção, por sua vez, está diretamente ligada ao que 


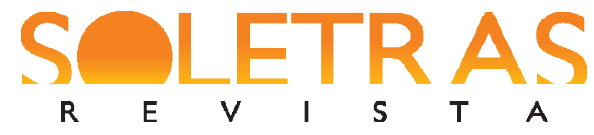

\section{N. 33 ï 2017.1 ï JOANA ANGÉLICA DA SILVA DE SOUZA} EDUARDO KENEDY

conseguimos compreender de um texto e a compreensão, seguindo o raciocínio apresentado, depende necessariamente da correlação entre o que está no texto e o que faz parte dos esquemas mentais frutos das leituras anteriores (e vivências) do indivíduo. Como podemos perceber, trata-se de um ciclo no qual leitura, compreensão e retenção das informações contidas em um novo texto dependem do que já foi lido, compreendido e retido anteriormente. Isso significa dizer que quanto mais se lê, mais facilidade se tem com novas leituras.

$\mathrm{Na}$ Internet, temos acesso a muita diversidade de informação, através de uma variedade enorme de textos, que em sua maioria são curtos e muitas vezes não são lidos por inteiro, pois realizamos um scanning e identificamos apenas a informação que nos interessa. É como se tivéssemos poucas informações sobre muitos temas.

Nesse cenário em que as leituras tendem a ser muito mais superficiais, é de se supor que ocorram ativações mais fracas dos esquemas mentais do indivíduo. Isso prejudicaria a criação de previsões, a apreensão dos sentidos contidos no que está sendo lido e, consequentemente, a retenção das informações.

Quando se confronta a ideia de que o cérebro é plástico e adaptável com o fato de que estamos mudando radicalmente nossos hábitos, fato que se comprova pela presença constante de tecnologias digitais em nossas vidas e tarefas rotineiras, intuímos as mudanças que estão ocorrendo em nossa forma de pensar, por consequência das novas arquiteturas cognitivas que as demandas do mundo virtual impõem ao cérebro. Nesse sentido, Small (2009) explica o que está por trás desse processo do ponto de vista biológico:

The current explosion of digital technology not only is changing the way we live and communicate but is rapidly and profoundly altering our brains. Daily exposure to high technology (é ) stimulates brain cell alteration and neurotransmitter release, gradually strengthening new neural pathways in our brains while weakening older ones (SMALL, 2009, p. 1). ${ }^{6}$

Para Gardner (2013), alguns aspectos da cognição humana são favorecidos pelo uso consciente de apps e outras tecnologias similares:

\footnotetext{
${ }^{6}$ A atual explosão de tecnologia digital não está somente alterando a forma como vivemos e nos comunicamos, mas está rápida e profundamente alterando nossos cérebros. A exposição diária a alta tecnologia (é ) estimula a alteração neuronal e a liberação de neurotransmissores, gradualmente fortalecendo novos caminhos neurais em nosso cérebro ao passo em que enfraquece caminhos antigos (tradução nossa).
} 
(...) with respect to imagination and creativity, digital technologies afford enormous potential for individual or group breakthroughs $\ddot{i}$ provided that the existing apps are treated as approaches to be built upon (allowing us to be app-enabled), rather than ones that constrict or constrain one $\hat{\theta}$ means and oneâs goals (causing us to become app-dependent) ${ }^{7}$ (GARDNER, 2013, p. 161).

Uma das vantagens que se vê nos novos dispositivos eletrônicos, tais como smartphones e tablets, que são utilizados também para leitura, é justamente a possibilidade de realização de diversas tarefas ao mesmo tempo através de um número incontável de aplicativos. O número de tarefas que se pode realizar em um desses aparelhos $\ddot{i}$ ao mesmo tempo, de preferência, Ï é diretamente proporcional ao sucesso que tal aparelho irá obter no mercado. A dispersão, característica inerente a algumas pessoas, acaba por ser acentuada de forma nunca antes vista com o uso desses dispositivos.

Em 2008, Small publicou uma pesquisa denominada Your Brain on Google: Patterns of Cerebral Activation during Internet Searching (Seu Cérebro no Google: Padrões de Ativação Cerebral durante a Pesquisa na Internet) como primeiro experimento que de fato mostrava as mudanças no cérebro que ocorriam em resposta ao uso da Internet. $\mathrm{O}$ experimento foi realizado utilizando a técnica de ressonância magnética e os participantes, divididos em dois grupos de acordo com a experiência no uso da Internet, realizavam buscas no Google. O resultado foi que o grupo dos usuários experientes apresentou um padrão de ativação da área do cérebro conhecida como córtex dorsolateral pré-frontal, responsável pela tomada de decisões, muito maior em comparação aos usuários inexperientes. Como controle, os participantes leram um texto corrido, simulando a leitura de uma página de livro e nenhuma diferença na atividade cerebral foi notada, o que significa que a alteração nas vias neurais observada na atividade de busca no Google foi realmente ocasionada pelo uso da Internet.

Esse experimento foi repetido seis dias depois e durante os cinco dias anteriores os usuários inexperientes passaram por um treinamento de apenas uma hora por dia usando a Internet. As diferenças na ativação da área do córtex dorsolateral pré-frontal entre os dois

\footnotetext{
7 (é ) com respeito à imaginação e criatividade, as tecnologias digitais proporcionam um enorme potencial para avanços individuais ou em grupo ï desde que os aplicativos existentes sejam tratados como abordagens com as quais se pode trabalhar (permitindo-nos estarmos habilitados para seu uso), em vez de comprimir ou restringir nossos meios e nossas metas (levando-nos a sermos dependentes deles) (tradução nossa).
} 


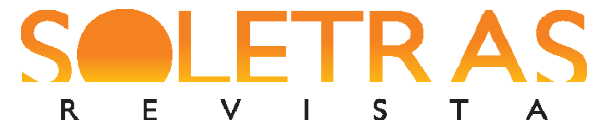

N. 33 ï 2017.1 ï JOANA ANGÉLICA DA SILVA DE SOUZA EDUARDO KENEDY

grupos diminuíram drasticamente e isso sugere que o tempo necessário para o cérebro se adaptar ao uso da tecnologia é muito pequeno.

A indagação que fazemos a partir de tal experimento é: se em tão pouco tempo o uso da Internet consegue alterar as vias neurais dos usuários e o padrão de ativação de certas áreas do cérebro durante a realização de uma tarefa, qual é o impacto cognitivo dessas alterações? A qualidade na realização das tarefas muda? Em que grau?

No Brasil, ainda não existem muitas pesquisas na área, mas podemos tomar como exemplo o artigo de Magalhães e Leite (2014), denominado ñMemorização e compreensão na leitura de textos manuscritos e digitadosò. Pensando em um contexto em que cada vez mais passamos a ler e escrever em dispositivos eletrônicos, o artigo reporta os resultados de um experimento que tem como objetivo verificar se, em termos de memória, podemos dizer que a leitura/escrita em meio digital e em papel são compatíveis.

A análise dos resultados indica que a leitura/produção de textos manuscritos se mostra mais eficiente em termos de memorização quando comparadas aos textos digitados. Cabe ressaltar que a variável de grupo não foi controlada, ou seja, o teste foi realizado por nativos digitais e imigrantes digitais.

A conclusão a que se chega é que as diferentes ativações motoras (no caso da escrita) e visuais (no caso da leitura) são capazes de modificar nossa atividade cerebral e influenciar o nível de memorização.

Como vimos, a retenção de informações é uma das etapas do processo de leitura. Izquierdo (2004) afirma que ña melhor recomendação possível para o exercício da prática da memória é lerò (IZQUIERDO, 2010, p. 62). Isso porque a leitura ativa a memória verbal, visual, de imagens e motora, sendo um dos mais completos ñexercíciosò para a mente como um todo. A memória pode ser definida como ña aquisição, a formação, a conservação e a evocação de informaçõesò (IZQUIERDO, 2002, p. 9).

Em termos neurológicos, as memórias se situam em neurônios e sinapses, que, como sabemos, são muito numerosos. Quando perdemos neurônios e as ligações entre eles e outros neurônios, perdemos as memórias que a eles estavam vinculadas. Como os neurônios não se reproduzem, a morte celular realmente significa o fim da memória. Mas, se há tantos recursos disponíveis $\ddot{i}$ bilhões de neurônios e possibilidades de interconexão entre eles $і ̈$ por que os neurônios morrem e por que esquecemos? A resposta é simples: porque nem sempre usamos 


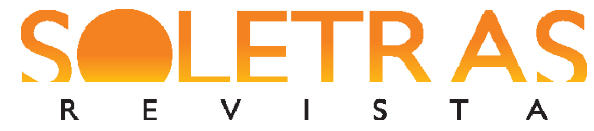

N. 33 ï 2017.1 ï JOANA ANGÉLICA DA SILVA DE SOUZA EDUARDO KENEDY

os neurônios vinculados às memórias de forma adequada. Claro, nem todos os esquecimentos têm a mesma causa, mas como nos afirma Izquierdo, ña maior parte dos esquecimentos resulta da falta de uso das sinapses. (...) quanto mais se usa a sinapse, melhor a função. Quanto menos se usa, pior a funçãoò (IZQUIERDO, 2010, p. 52-53).

Isso significa que se ao longo do tempo estamos perdendo o hábito de nos concentrar para ler textos longos e refletir sobre eles por causa de dispositivos digitais, a cada dia teremos mais dificuldade para fazê-lo. Naturalmente, não perderemos a memória de como decodificar letras e palavras, pois essa é uma tarefa incorporada em nossa memória procedimental e que continuamos a exercitar durante a navegação na Internet.

A tendência é que em uma pessoa que abandone totalmente a leitura de livros e passe a ler exclusivamente textos na Internet, as etapas mais profundas e extralinguísticas do processo de leitura sofram com a falta do exercício da leitura concentrada, que é facilitada no texto impresso em comparação com o meio digital. Tais etapas demandam concentração e reflexão sobre o material escrito, como a interpretação e a retenção de informações do texto e a falta de seu exercício atrapalharia a formação de novos esquemas cognitivos, afetando o processamento de novos textos.

Além disso, o uso exacerbado de Internet, com informações de múltiplas naturezas sendo processadas com uma velocidade maior do que o usual, tende a sobrecarregar a memória de trabalho, causando falhas na mesma. Isso significa que não estamos perdendo nossa capacidade de memória, mas que estamos dando outro uso para a nossa memória ñinternaò. A Internet está funcionando como uma espécie de ñmemória externaò de nossas mentes, estamos nos adaptando ainda mais à necessidade de recuperar informação que não está em nossa mente.

Obviamente, isso não se iniciou com a Internet, pois mesmo antes dela sabíamos como pesquisar em dicionários e em enciclopédias. A questão é que a intensificação desse processo, mesmo que nos leve a um aprimoramento da nossa capacidade de julgamento e pesquisa, pode nos deixar menos autônomos em termos de conhecimento.

Como Izquierdo (2010) pontua na epígrafe de $A$ arte de esquecer, ñada um de nós é quem é porque tem suas próprias memóriasò. Essa não é uma capacidade descartável, pois faz parte da nossa essência enquanto seres humanos. Isso não significa que devemos frear os avanços tecnológicos, mas que devemos pensar em formas de não prejudicar nossa memória. 


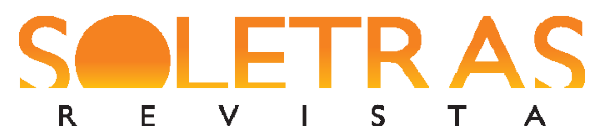

Deixar de ler livros não é prejudicial apenas ao processamento de novos textos escritos. A leitura concentrada de ficção é a atividade mais completa em termos de exercício dos neurônios e sinapses, ativando diversas áreas do cérebro:

Não sabemos com precisão quais sinapses são usadas para cada memória. Sabemos, sim, onde estão: no hipocampo, no núcleo da amígdala e nas conexões de ambas as estruturas entre si e com o resto do cérebro, fundamentalmente o córtex. No córtex, é evidente que as memórias visuais utilizarão o córtex visual e toda a via que vai desde a retina até esse córtex. Nas memórias que requeiram a evocação ou a formação de imagens, muitas áreas do córtex visual e associativo. Nas memórias verbais, utilizaremos as regiões vinculadas à linguagem, no córtex frontal, parietal e temporal. Nas memórias com um componente motor importante, o córtex motor; e assim por diante. Uma atividade que requer a utilização de todas estas regiões é a simples leitura (IZQUIERDO, 2010, p. 61).

Concluímos, portanto, algo que muitos de nós já repetimos incessantemente aos nossos alunos e aos mais jovens: ler é muito importante. Não apenas por ser a melhor forma de se informar, conhecer outras realidades e dar espaço à imaginação, mas também para fortalecer nosso cérebro e nossa cognição.

Enquanto a leitura de um livro se constitui em um exercício para a concentração, pois é uma atividade que exige nosso foco e aplaca nosso anseio por estímulos, a Internet funciona exatamente ao contrário. $\mathrm{Na}$ Internet, ficamos em um estado de desatenção constante, saltando entre as mensagens de amigos, as redes sociais, a pesquisa do Google e as outras inúmeras possibilidades que ela nos apresenta. Isso, naturalmente, não significa que estamos fadados a não conseguirmos mais focar em uma única atividade.

Da mesma forma que o esquecimento é importante para a memória, a distração também é importante, é impossível e desaconselhável estar atento o tempo inteiro. Não precisamos abandonar nossos computadores. No entanto, a prática da leitura concentrada ï e por lazer, de preferência $і ̈$ também precisa fazer parte das nossas atividades rotineiras para que possamos tirar melhor proveito das novas ferramentas sem perdermos a antiga, e essencial, capacidade de concentração.

Como a metodologia da presente pesquisa é experimental, idealizamos um experimento que conseguisse testar as teorias acima expostas. Incluímos a testagem dos 


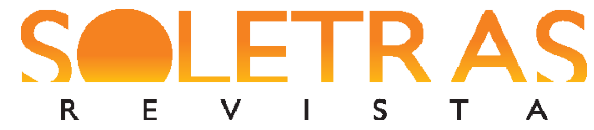

N. 33 Ï 2017.1 Ï JOANA ANGÉLICA DA SILVA DE SOUZA EDUARDO KENEDY

processos de compreensão de texto e também memória e concentração, pois estas são habilidades extralinguísticas envolvidas diretamente com a leitura.

\section{Metodologia}

O teste selecionado para o experimento foi o Teste de Cloze (TAYLOR, 1953), que é um modelo de testagem de compreensão de textos aceito dentro do campo da Linguística Aplicada e da Psicologia, criado para medir o nível de compreensibilidade de um determinado texto por parte do leitor e se fundamenta na Teoria da Informação e na ideia de amostra aleatória (ADELBERG; RAZEK, 1984). ñLogo se descobriu que o Cloze não media apenas a inteligibilidade do texto, mas era também um instrumento válido e confiável para medir a proficiência de leitura; a variação de acertos no teste discrimina fidedignamente o leitor fluente do leitor fracoò (LEFFA, 1996, p. 70).

O teste consiste em retirar palavras de um texto aleatoriamente e substituí-las por lacunas a serem preenchidas pelos participantes. Assim, quanto mais lacunas forem preenchidas corretamente, de acordo com critérios de coesão e coerência, maior será o score do participante no que se refere à compreensão.

Para realizar o teste, o participante precisa reconstruir a mensagem do texto, demonstrando que conseguiu cumprir satisfatoriamente com todas as etapas de leitura já mencionadas. Por isso, a técnica vem sendo utilizada para medir não só a inteligibilidade de um texto, mas também a proficiência da leitura e a competência linguística, sendo utilizado inclusive para o ensino (LEFFA, 1996).

A nossa hipótese é que os nativos digitais se distraiam mais durante a tarefa de leitura e preenchimento das lacunas e, consequentemente, preencham mais lacunas de forma incoerente com o texto, demonstrando uma pior compreensão dos sentidos nele veiculados. Ainda nesse sentido, a opção pelo teste de Cloze se deu em função do fato de ser um teste que demanda do indivíduo a capacidade de decodificação do material linguístico do texto, mas que exige principalmente uma associação de seu conhecimento extralinguístico e de processos de interpretação mais profundos para a elaboração de hipóteses quanto ao preenchimento das lacunas. 


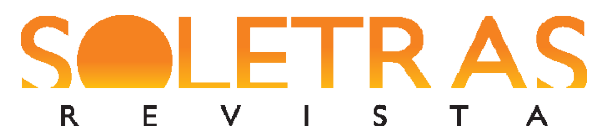

Para fins de comparação do comportamento cognitivo entre os grupos, nativos e imigrantes digitais, comparamos o desempenho de participantes classificados como nativos digitais com o dos classificados como imigrantes digitais em termos de compreensão do texto (score de erros) e memória (número de palavras recordadas), conforme mostrado no capítulo dedicado aos resultados da pesquisa.

Para realizar o Teste de Cloze, seguimos as seguintes etapas: a) selecionamos o texto a ser avaliado; b) excluímos a décima sexta palavra e, a partir dela, toda quinta palavra do trecho selecionado foi retirada e substituída por lacunas de tamanho único; c) o texto foi apresentado aos participantes, que não entraram em contato previamente com o texto integral; d) instruiu-se que os participantes preenchessem as lacunas com as palavras que acreditassem terem sido retiradas, informando que não havia um gabarito a ser seguido, qualquer palavra que completasse o sentido do texto seria válida. Por fim, consideramos corretas as respostas que completaram a lacuna de forma a manter a coesão e a coerência do texto.

Quando o participante devolvia o texto com as lacunas preenchidas, entregávamos a ele uma folha contendo 10 palavras que ele deveria julgar se estavam presentes no texto ou não, com o objetivo de avaliar sua memória.

Como podemos perceber, o método é off-line (não cronométrico), pois se trata de uma aferição feita em um momento posterior ao do processamento linguístico, ainda que imediatamente subsequente a este.

As variáveis dependentes foram o score de acerto no Teste de Cloze e o número de palavras recordadas do texto. As variáveis independentes foram a classificação em nativo digital ou imigrante digital de acordo com o questionário, o meio utilizado para a leitura (papel ou computador) e o tamanho do texto (curto ou longo).

Temos, portanto, oito condições experimentais. A saber: (1) Nativos digitais lendo texto longo em papel; (2) Nativos digitais lendo texto longo em tela; (3) Nativos digitais lendo texto curto em papel; (4) Nativos digitais lendo texto curto em tela; (5) Imigrantes digitais lendo texto longo em papel; (6) Imigrantes digitais lendo texto longo em tela; (7) Imigrantes digitais lendo texto curto em papel; e (8) Imigrantes digitais lendo texto curto em tela.

Quanto ao material, usamos um texto, com uma versão curta e uma versão longa. O gênero do texto selecionado foi crônica, por ser um gênero jornalístico, com grau de 


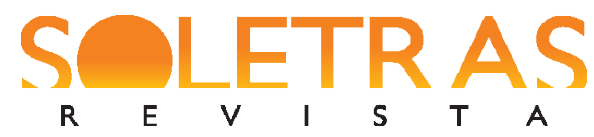

complexidade baixo, ainda que ficcional. Para avaliar o nível de concentração, comparamos o resultado nas questões referentes aos textos curtos e longos.

As tarefas realizadas pelos participantes foram divididas em dois momentos: no primeiro momento, tivemos a resposta a um questionário que avaliava a idade e os padrões de uso de ferramentas digitais, que serviu para classificar os participantes em nativos ou imigrantes digitais. Em um segundo momento, entramos em contato com os participantes selecionados de acordo com o perfil de acesso à Internet e agendamos horários com cada um deles.

Dividimos os grupos dos nativos digitais e dos imigrantes digitais em 4 subgrupos cada: (1) os que leram a versão longa do texto selecionado no computador; (2) os que leram a versão longa do texto selecionado no papel; (3) os que leram a versão curta do texto selecionado no computador; e (4) os que leram a versão curta do texto selecionado no papel.

Cada participante recebeu a instrução de ler o texto recebido e preencher as lacunas com palavras que consideravam que completariam o sentido do texto. Os participantes que realizaram a tarefa no computador, utilizaram o programa Microsoft Word, pela maior familiaridade com o programa em relação a outras plataformas. Depois, sem acesso ao texto, cada participante julgou se as 12 palavras que apresentamos faziam parte do texto.

O questionário foi aplicado a um total de 122 alunos de nível superior da Universidade Federal Fluminense dos períodos iniciais dos cursos de Letras e Jornalismo e, dentre eles, selecionamos dois grupos: os maiores de 40 anos e os menores de 25 anos. Dentro do grupo dos maiores de 40, selecionamos os oito que se propuseram a participar do experimento seguindo a ordem de menor pontuação no questionário para montar o grupo de imigrantes digitais. Já para formar o grupo de nativos digitais, selecionamos as 24 maiores pontuações dentro do grupo dos menores de 25 anos dentre os participantes que estavam disponíveis para a aplicação do experimento. A distribuição foi entre sujeitos, ou seja, os participantes não estavam expostos às mesmas condições experimentais.

\section{Resultados}

As médias dos resultados obtidos nos testes foram registradas nas tabelas a seguir e submetidas aos testes estatísticos Qui-quadrado de Aderência, Homogeneidade e 


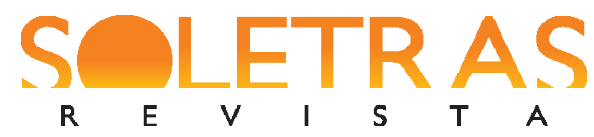

Independência para depreender a validade das respostas e o comportamento das variáveis no resultado do experimento.

Média dos Resultados dos Imigrantes Digitais

\begin{tabular}{|c|c|c|c|c|}
\hline \multirow{2}{*}{ Var. Ind. } & \multicolumn{4}{|c|}{ Imigrantes Digitais (ID) } \\
\cline { 2 - 5 } & \multicolumn{2}{|c|}{ Texto Longo (TL) } & \multicolumn{2}{c|}{ Texto Curto (TC) } \\
\cline { 2 - 5 } & Papel (LP) & Tela (LT) & Papel (LP) & Tela (LT) \\
\hline Score no teste (ST) & 86 & 73,5 & 73,16 & 57,31 \\
\hline $\begin{array}{c}\mathrm{N}^{\circ} . \text { de Palavras } \\
\text { Recordadas (PR) }\end{array}$ & 66,66 & 50 & 77,77 & 54,16 \\
\hline
\end{tabular}

Média dos Resultados dos Nativos Digitais

\begin{tabular}{|c|c|c|c|c|}
\hline \multirow{2}{*}{ Var. Ind. } & \multicolumn{4}{|c|}{ Nativos Digitais (ND) } \\
\cline { 2 - 5 } Var. Dep. & \multicolumn{3}{|c|}{ Texto Longo (TL) } & \multicolumn{2}{c|}{ Texto Curto (TC) } \\
\cline { 2 - 5 } & Papel (LP) & Tela (LT) & $\begin{array}{c}\text { Papel } \\
\text { (LP) }\end{array}$ & Tela (LT) \\
\hline Score no teste (ST) & 88,16 & 87,5 & 84,23 & 82,11 \\
\hline $\begin{array}{c}\mathrm{N}^{\circ} \text {. de Palavras } \\
\text { Recordadas (PR) }\end{array}$ & 65,27 & 62,49 & 73,6 & 66,66 \\
\hline
\end{tabular}

A partir dos testes estatísticos, realizamos as análises que seguem. A variável independente tamanho do texto teve um efeito inesperado em nossos resultados. A hipótese inicial era de que os participantes teriam mais dificuldade para interpretar o texto longo pela necessidade de se concentrar por um período de tempo maior, no entanto, pelos testes estatísticos, não pudemos rejeitar a hipótese nula $\left(H_{0}\right)$. Isso pode gerar três interpretações possíveis: a primeira está ligada ao fato de que a diferença no tamanho do texto não foi suficiente para causar um problema de concentração, a segunda ao fato de que o texto longo forneceu mais informações ao participante, que conseguiu ter mais base para preencher as lacunas do Teste de Cloze e a terceira interpretação se refere ao fato de que nativos digitais e imigrantes digitais não apresentam dificuldades quanto à concentração independente do suporte da leitura. O mesmo se aplica à memória, o que indica que o tamanho do texto foi irrelevante para a retenção de informações lexicais.

Quanto à variável independente de grupo, tivemos um resultado melhor no grupo dos nativos digitais em quase todas as condições. A única exceção foi no teste de memória na 


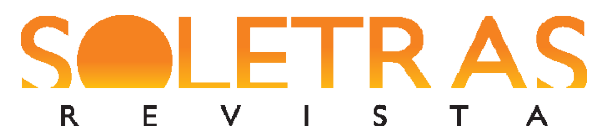

leitura em papel. Isso contraria a hipótese levantada a partir das reflexões de Carr (2011) de que o uso de Internet desde os primeiros estágios de vida pode ter um impacto negativo para a compreensão de textos. No entanto, nossos resultados não nos permitem afirmar que os nativos digitais estão lendo melhor que os imigrantes digitais porque apesar de termos controlado a variável escolaridade, a fim de homogeneizar o grupo experimental e o grupo controle, percebemos que existe uma discrepância muito grande no nível de conhecimento e nos hábitos de leitura entre os ingressantes, o que influencia no nosso resultado.

No Teste de Cloze, todos os resultados no papel foram melhores em comparação com os resultados na tela, o que significa que ler em um meio digital ainda acarreta uma sobrecarga cognitiva e gera um decréscimo na nossa capacidade de compreender um texto. No entanto, quando realizamos o teste de proporção para cada grupo, vimos que o meio de leitura só teve efeito para o grupo dos nativos digitais. Isso pode indicar que as próximas gerações terão cada vez menos prejuízos com a leitura em meios digitais.

No teste de memória, esse padrão se repete. Enquanto os nativos digitais têm desempenho ligeiramente superior no papel, os imigrantes digitais têm um desempenho muito superior no papel, o que nos faz questionar: será que isso indica que a cada geração que passa, teremos menos prejuízos com a leitura em meios digitais?

Quando fizemos o teste de proporção para o grupo dos nativos e para o grupo dos imigrantes, encontramos um resultado estatisticamente não significativo ( $p>.05)$ para o grupo dos nativos digitais e estatisticamente significativo $(\mathrm{p}<.05)$ para o grupo dos imigrantes digitais. Já quando juntamos os dois grupos, o resultado foi significativo $(\mathrm{p}<.05)$, conforme mostrado no gráfico abaixo. 

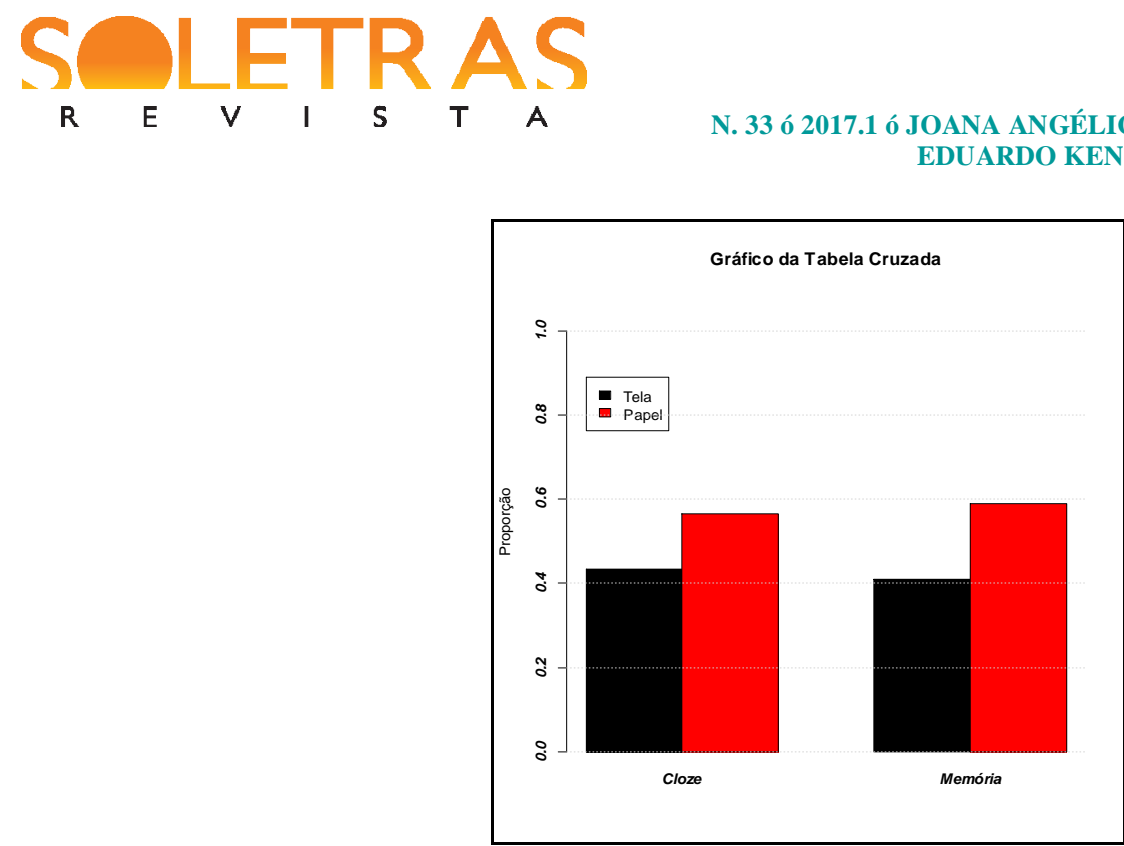

Gráfico da Tabela Cruzada para a Variável Suporte de Leitura

Esse resultado indica que quando juntamos nativos e imigrantes digitais, o suporte de leitura é uma variável relevante, ou seja, rejeitamos a hipótese nula $\left(H_{0}\right)$. Conforme observado no gráfico acima, tanto no teste de Cloze quanto no teste de memória, os participantes se saíram melhor quando realizaram as tarefas no papel em comparação com a tela do computador, corroborando os resultados encontrados por Magalhães e Leite (2014).

\section{Conclusão}

A partir do referencial teórico, adotamos como hipótese a ideia de que os nativos digitais leem de forma mais superficial que os imigrantes digitais (CARR, 2011). Sendo a leitura uma atividade extremamente complexa do ponto de vista cognitivo (DEHAENE, 2009), é de se imaginar que a leitura em um suporte que promova a dispersão provoque um encargo cognitivo em relação à leitura em papel. No entanto, conforme já apresentado, os nativos digitais se saíram melhor que os imigrantes digitais nas tarefas de leitura e memória.

Por um lado, esse resultado nos mostra que, apesar das diferenças neurológicas observadas no cérebro dos nativos digitais por conta da reorganização cortical causada pelo uso de ferramentas digitais (SMALL, 2009), não precisamos ficar tão alarmados quanto aos estragos dessas mudanças, é possível que elas não causem déficits tão preocupantes quanto podemos pensar a princípio. 


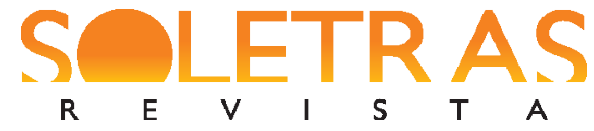

N. 33 ï 2017.1 ï JOANA ANGÉLICA DA SILVA DE SOUZA EDUARDO KENEDY

A análise dos resultados nos aponta ainda para a necessidade de ter muito cuidado ao escolher os participantes de experimentos dessa natureza e para a importância da tentativa de minimizar os efeitos de possíveis variáveis de confusão nos resultados. Apesar de termos controlado a variável escolaridade no experimento, isso não foi suficiente para garantir que os dois grupos ficassem homogêneos em termos socioculturais, o que acabou por influenciar no resultado.

Apesar disso, nosso experimento indicou que o tamanho do texto não teve efeito para o resultado do teste e o suporte foi, sim, relevante para a eficiência da leitura, sobretudo dentre os imigrantes digitais. Somente a realização de mais experimentos que levem em consideração os achados da presente pesquisa pode fornecer respostas mais sólidas e confiáveis a respeito do nosso objeto.

Esperamos que essas conclusões possam ser importantes para o desenvolvimento de um conhecimento mais consolidado a respeito do impacto cognitivo da tecnologia em nosso cotidiano e, especificamente, a respeito dos efeitos do uso de meios digitais para a leitura e as diferenças entre meios digitais e papel no que se refere a como interpretamos informações.

Ainda que não se possa afirmar categoricamente, nossos resultados sugerem que o uso de meios digitais como suporte para a leitura causa um prejuízo na eficiência da mesma. Tal fato é preocupante para a sociedade, visto que no Brasil a leitura ainda é um problema muito grave em termos educacionais. Com o uso das novas tecnologias se expandindo cada dia mais entre jovens e idosos de todas as camadas sociais, as consequências podem ser negativas.

Apesar de nossos resultados sugerirem que a leitura é mais eficiente em papel, o fato é que estamos apenas no início da busca por mais evidências de quais são os impactos das mudanças neurológicas que estão ocorrendo em nosso cérebro para as atividades intelectuais do dia a dia, como é o caso da leitura.

Sendo assim, concluímos que a Psicolinguística, estudo com uma perspectiva cognitiva sobre o comportamento linguístico humano, tem ainda grandes contribuições a fazer para a sociedade no que se refere à leitura e ao ambiente virtual, na medida em que as conclusões tiradas a partir de pesquisas experimentais podem $\ddot{i}$ e devem $\ddot{i}$ dialogar com as pesquisas pedagógicas sobre o tema.

\section{Referências}




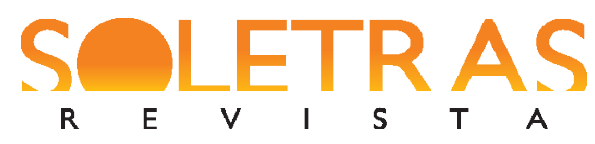

ADAMS, M. J. Reading. In: WILSON, R. A; KEIL, F. C. The MIT encyclopedia of the cognitive sciences. Cambridge, MA: MIT Press, 1999.

ADELBERG, A. H.; RAZEK, J. R. The cloze procedure: a methodology for determining the understandability of accounting textbooks. The Accounting Review, 1984.

ALTMANN, G; STEEDMAN, M. Interaction with context during human sentence processing. Cognition, 30, 191-238, 1988.

ALVES, S. V. Trabalhando as inteligências múltiplas em sala de aula. Brasília, DF: Plano Editora, 2003.

BARTLETT, Frederic. Remembering: a study in experimental and social psychology. Cambridge University Press, 1961.

BRIGGS, A.; BURKE, P. A social history of the media: from Gutenberg to the Internet. Cambridge: Polity Press, 2002.

CABRAL, L. S. Processos psicolinguísticos de leitura e a criança. Porto Alegre: Letras de Hoje, v. 19, n. 1, pp. 7-20, 1986.

Guia prático de alfabetização, baseado em princípios do Sistema alfabético do Português do Brasil. São Paulo: Contexto, 2003.

CAIRO, A., MOON, P. e SORG, L. A Internet faz mal ao cérebro. Época, 29 out. 2011. Disponível em: <http://revistaepoca.globo.com/ideias/noticia/2011/10/Internet-faz-mal-aocerebro-trecho.html>. Acesso em 30 ago. 2014.

CAPOVILLA, A; GÜTSCHOW, C; CAPOVILLA, F. Habilidades cognitivas que predizem competência de leitura e escrita. Psicologia: teoria e prática, 2004, n. 6, v. 2, p. 13-26.

CARR, N. A geração superficial: o que a Internet está fazendo com nossos cérebros. Rio de Janeiro: Agir, 2011.

CHOMSKY, N. Linguagem e pensamento. Petrópolis, RJ: Vozes, 1971.

CRAIN, S; STEEDMAN, M. J. On not being led up the garden path: the use of context by the psychological parser. In: KARTTUNEN, D. Dowty, L; ZWICKY, A. (Eds.). Natural language parsing: psychological computational, and theoretical perspectives. Cambridge: Cambridge University Press, 1984.

DEHAENE, S. Reading in the brain: a new science of how we read. New York: Viking Penguin, 2009.

FERES, B. Arnaldo Antunes, inferenciação e sentimento: fundamentos semiolinguísticos para aula de leitura, 2010. Disponível em: http://www.filologia.org.br/xiv_cnlf/tomo_1/535547.pdf. 


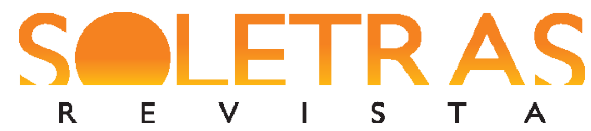

N. 33 ï 2017.1 ï JOANA ANGÉLICA DA SILVA DE SOUZA EDUARDO KENEDY

FERREIRO, E; TEBEROSKY, A. Psicogênese da língua escrita. Porto Alegre: Artes Médicas, 1986.

FODOR, J. A. Modularity of mind: an essay on faculty psychology. Cambridge, Mass.: MIT Press, 1983.

FOUCAMBERT, J. A leitura em questão. Porto Alegre: Artes Médicas. 1994.

FREIRE, Paulo. A importância do ato de ler. 23. ed. São Paulo: Cortez, 1989.

GARDNER, H. The App Generation: how todayôs youth navigate identity, intimacy and imagination in a digital world. New Haven: Yale UP, 2013.

GARROD, S; DANEMAN, M. Reading, psychology of. In: Encyclopedia of cognitive science, v. 3. London: Nature Publishing Group, 2003.

GOODMAN, K. S. Unidade na leitura: um modelo psicolinguístico transacional. Letras de Hoje, n. 86, p. 9-43, Porto Alegre, EDIPUCRS, dez. 1991.

IBGE. Instituto Brasileiro de Geografia e Estatística. Disponível em: <http://www.ibge.gov.br/home/presidencia/noticias/imprensa/ppts/000000129623051220132 34016242127.pdf>. Acesso: 8 mai. 2015.

IPM. Instituto Paulo Montenegro. $3^{\circ}$ Indicador Nacional de Analfabetismo Funcional Disponível em: http://www.ipm.org.br/download/inaf03.pdf. Acesso em 8 mai. 2015.

IZQUIERDO, I. Memória. Porto Alegre: Artmed, 2002.

A arte de esquecer. Rio de Janeiro: Vieira e Lent, 2010.

JERÔNIMO, G. O processamento da leitura e as especificidades dos hemisférios cerebrais. 2012. Disponível em: http://online.unisc.br/seer/index.php/signo/article/download/2980/2326. Acesso: 06 abr. 2016.

KATO, M. O aprendizado da leitura. 5. ed. São Paulo: Martins Fontes, 1999.

KENEDY, E. Curso básico de linguística gerativa. SP:Contexto, 2013.

KLEIMAN, A. Texto e leitor: aspectos cognitivos da leitura. Campinas, SP: Pontes, 2007.

LEFFA, Wilson. Aspectos da leitura. Porto Alegre: Sagra-DC Luzzato, 1996.

MAGALHÃES, J. O; LEITE, C. T. Memorização e compreensão na leitura de textos manuscritos e digitados. Revista LinguíStica, Revista do Programa de Pós-Graduação em 


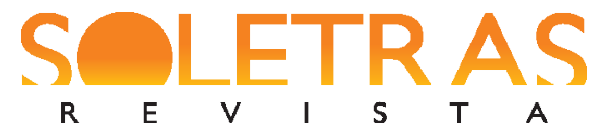

N. 33 ï 2017.1 ï JOANA ANGÉLICA DA SILVA DE SOUZA EDUARDO KENEDY

Linguística da Universidade Federal do Rio de Janeiro, v. 10, n. 1, jun. 2014. Disponível em: <http://www.letras.ufrj.br/poslinguistica/revistalinguistica>. Acesso: 25 ago. 2014.

MORAIS, J. A arte de ler. Trad. Álvaro Lorencini. São Paulo: Editora da Universidade Estadual Paulista, 1996.

SIQUEIRA, E. Revolução digital: história e tecnologia no século 20. São Paulo: Saraiva, 2007.

PEREIRA, V. W; GUARESI, R. (Orgs.). Estudos sobre leitura: psicolinguística e interfaces.Porto Alegre: EDIPUCRS, 2012.

PRENKSY, M. Digital Natives, Digital Immigrants. In: On the Horizon (MCB University Press, Vol. 9 No. 5, October 2001). Disponível em: <http://www.marcprensky.com/writing/Prensky\%20\%20Digital\%20Natives, \%20Digital\%20I mmigrants\%20-\%20Part1.pdf> . Acesso 25 ago. 2014.

ROSSI, J. O ambiente digital está alterando nosso cérebro de forma inéditaò, diz neurologista britânica. Veja, 30 set. 2012. Disponível em: <http://veja.abril.com.br/noticia/ciencia/oambiente-digital-esta-alterando-nosso-cerebro-de-forma-inedita-diz-neurologista-britanica $>$. Acesso: 30 ago. 2014.

ROWAN, C. 10 razões pelas quais os aparelhos móveis devem ser proibidos para crianças menores de 12 anos. Brasil Post, 24 mar. 2014. Disponível em: http://www.brasilpost.com.br/cris-rowan/tecnologia-criancas_b_5020937.html. Acesso: 14 abr. 2015.

SANTOS, A. A. A. Diagnóstico de compreensão de leitura por meio do teste de Cloze. Programa de Pós-Graduação Stricto Sensu em Psicologia. Universidade São Francisco. Itatiba, 2002.

SAUSSURE, F. Curso de Linguística Geral. São Paulo: Ed. Cultrix, 2006.

SCHWARTZ, J. M; BEGLEY, S. The mind and the brain: neuroplasticity and the power of mental force. Harper Perennial, 2002.

SMALL, G. W. iBrain: surviving the technological alteration of the modern mind. New York: Harper, 2009.

SMITH, F. Compreendendo a leitura: uma análise psicolinguística da leitura e do aprender a ler. $4^{\mathrm{a}}$ ed. Porto Alegre: Artmed, 2003.

SOLÉ, I. Estratégias de leitura. 6. ed. Porte Alegre: Artes Médicas, 1998. 


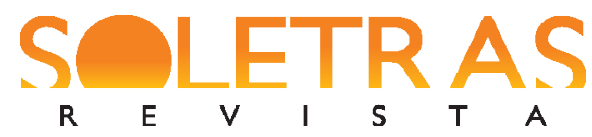

N. 33 ï 2017.1 ï JOANA ANGÉLICA DA SILVA DE SOUZA EDUARDO KENEDY

SPARROW, B. Google effects on memory: cognitive consequences of having information at our fingertips Disponível em: http://www.wjh.harvard.edu/ wegner/pdfs/science.1207745.full.pdf. Acesso: 02 jun. 2015.

ESTEFENON, E; EISENSTEIN, S. B. Geração digital: risco das novas tecnologias para crianças e adolescentes, 2008.2 Disponível em: http://revista.hupe.uerj.br/audiencia_pdf.asp?aid2=105\&nomeArquivo=v10s2a06.pdf.

Acesso: 06 abr. 2016.

STERNBERG, R. J. Psicologia cognitiva. São Paulo: Cengage Learning, 2012.

STRASBURGER, V; MARJORIE, H, Children, Adolescents, and the Media. PEDIATRICS, v. 132, n. 5, nov. 1, 2013, p. 958-961. Disponível em: http://pediatrics.aappublications.org/content/132/5/958.full. Acesso em: 14 abr. 2015.

SOUZA, V. N. Nível de compreensão de leitura de um aluno colombiano no processo de aprendizagem do português: um estudo de caso. In: PEREIRA, V. W; GUARESI, R. (Orgs.). Estudos sobre leitura: psicolinguística e interfaces. Porto Alegre: EDIPUCRS, 2012.

TAYLOR, W. L. Cloze procedure: a new tool for measuring readability. Journalism Quarterly, 30, p. 415-433, 1953.

Cloze readability scores as indices of individual differences in comprehension and aptitude. Journal of Applied Psychology, 1957.

VEIGA, E. C. Psicopedagogia e a teoria modular da mente: uma nova perspectiva para a aprendizagem. São José dos Campos, SP: Pulso, 2006.

WOLF, M. Proust and the squid. Harper Collins Publishers, 2008.

\title{
Digital nativesôreading: a psycholinguistic approach
}

\begin{abstract}
Considering the phenomenon known in neuroscience as brain plasticity (SCHWARTZ, 2002) and the theoretical scope of Psycholinguistics on reading, recent researches suggest that the use of Internet facilitates the ability to multitask, which would cause a disturbing cognitive burden: the gradual loss of our capacity for deep reflection and concentration. This context generates two basic questions: (i) How these changes in our cognitive behavior can affect our ability to decode and assign meanings to what we read? (ii) The new generation, known as the digital natives (PRENSKY, 2001), is more susceptible to these changes by early exposure to virtual environments? The objectives of this research are: find possible problems in reading comprehension and retention of information by digital natives and investigate possible differences in reading in digital and print media by digital natives and digital immigrants. We will use the experimental methodology, with the participants performing a gap-filling task in the model of the Cloze Test (TAYLOR, 1953) and a test of memory/recognition of the words presented in the text. The dependent variables are the number of words filled that are
\end{abstract}




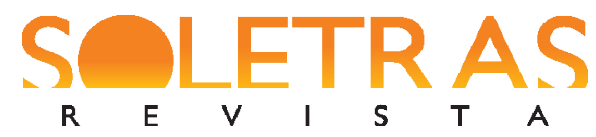

consistent with the meaning of the text and the number of words remembered, while the independent variables are the classification in digital immigrant or digital native, the medium used for reading, paper or computer, and the text size, short or long. Not all subjects were exposed to the same experimental conditions (between subjectô design).

Keywords: Reading. Reading Comprehension. Cognition. Internet. Psycholinguistics.

Recebido em: 29 de maio de 2017.

Aprovado em: 07 de junho de 2017. 